\title{
Retraction Note to: Occurrence, spread and control measures of Bothriocephalus acheilognathi (Bothriocephalidae: Cestoda)
}

\author{
Tanveer A. Sofi ${ }^{1} \cdot$ Fayaz Ahmad $^{1} \cdot$ Bashir A. Sheikh ${ }^{1}$
}

Published online: 1 December 2018

(C) Indian Society for Parasitology 2018

\section{Retraction Note to: J Parasit Dis \\ (July-Sept 2016) 40(3):1096-1108 \\ https://doi.org/10.1007/s12639-014-0568-6}

The Editor-in-Chief has retracted this article by Sofi et al. (2016) because the article shows significant overlap with a book chapter by Scholz et al. (2012). All authors agree to this retraction.

\section{References}

Scholz T, Kuchta R, Williams C (2012) Bothriocephalus achelognathi. In: Woo PTK, Buchmann K (eds) Fish parasites. Pathobiology and protection, Chapter 17. CAB International, Wallingford, pp 282-297

Sofi TA, Ahmad F, Sheikh BA (2016) Occurrence, spread and control measures of Bothriocephalus acheilognathi (Bothriocephalidae: Cestoda). J Parasit Dis 40:1096. https://doi.org/10.1007/s126 39-014-0568-6

The original article can be found online at https://doi.org/10.1007/s12639-014-0568-6.

Tanveer A. Sofi

stanveer96@gmail.com

Fayaz Ahmad

rajafayazali@yahoo.co.in

1 Post Graduate Department of Zoology, University of Kashmir, Srinagar 1900 06, India 